\title{
Physical Activity of Young Persons and Importance of Involvement of Parents to Increase Their Performance
}

\author{
Rovena Elmazi \\ Sport University of Tirana,Faculty of Physical Activity and Recreation , Departament of Organization\& Menagement \\ rd.elmazi@gmail.com
}

Migena Plasa

Institute of sport Research,Sport University of Tirana

\begin{abstract}
Game and physical activity are the main tools for children to learn because they learn quickly through personal expenience and multi-sensor teaching methods which encourage their natural sense of curiosity. Game, in all its forms, presents numerous possibilities for interaction of children with persons and objects in real and imaginary situations. Small children must have a committed specialist to interact even with the parents. In this way children willtry hard to improve what they know better by helping and inspiring them as a way promoting interest and will to continue learning. Scholars consider quite positive the involvement of parents in the learning process because parents are constantly informed of the situation and progress of their children. This applies even to the classes of physical education and training sessions in all sports disciplines where teacherparent cooperation would strongly affect the improvement of their children performance. By knowing better the specifics of sports activities and its role in their psycho-motor development, there have to be used all the possibilities toencourage children to be involved in sports activities and there have to be found all the possibilities to increase their performance. From ower experience as teacher of physical education, trainer of young ages and professional basketballer I have learned that involvement of parents and cooperation with them is extremely useful and this is the reason why I have elaborated further on this topic. An ideal environment for the children is a teaching environment of work flow, high quality and careful programme planning.
\end{abstract}

Keywords: teacher, parent, cooperation, physical activity, motor development

\section{Introduction}

There are various perceptions of scholars concerning parents' involvement in the teaching process. Scholars group parents' involvement into two categories: home-based involvement and school-based involvement. Sheldon (2003) defines homebased involvement as a parent-child interaction in relation to school or other learning activities and he introduces the concept of direct investment of parent's sources in the education of children. School-based involvement concerns the possibilities of involvement and regular communication with the. According to Leving, parents' involvement must be encouraged because positive messages which are important for the education of children, will be send to the latter. It is important for parents to be frequently informed of the performance of their children even through their conversation with the children. In this way children are encouraged to make utmost efforts knowing that they will be supported and their selfconfidence will be improved. In the long run, the situation of child, the parent-child relations will be improved and a positive attitude of parents in relation to the teacher, trainer, team and its managers will be developed.

In 1996, Griffit undertook a study in the school premises to see the involvement and satisfaction of parents. School climate is closely linked to the parents' satisfaction resulting from their being informed. Griffit found that parents were mostly involved in educational activities rather than second-hand activities of our academic system. The same finding applies to our country. This wrong approach must be changed because physical activity is extremely important in the psycho-motor development of children and parents' involvement is as important in the attainment of the objectives 


\section{Aim and object of the study}

The aim of this study is to promote parents' involvement during training of their children in various sports activities and improve quality of training of children considering the parent as the success key for the young age who are on the focus of this study. Parents must be encouraged to attend and join several activities performed by their child in order to reproduce them in other premises- repeating all the movements and having some joyful moments with their children.

The object of this study is: assessment of involvement of parents in the school system and during physical activity outside the school system in Tirana.

\section{Methodology}

The study is based on two standard questionnaires, one addressed to parents and one addressed to the teachers of physical education and trainers in Tirana based on Likert scale. The questionnaire consists of several questions of Likert scale which define five possible answers: strongly disagree/disagree /undecided/agree/strongly agree. The study will be focused on parents of children aged 6-10 years and also specialists working with this age group because they are the age groups on which the study is based.

\section{Result}

Results obtained from the questionnaire addressed to teachers and trainers are as follows:

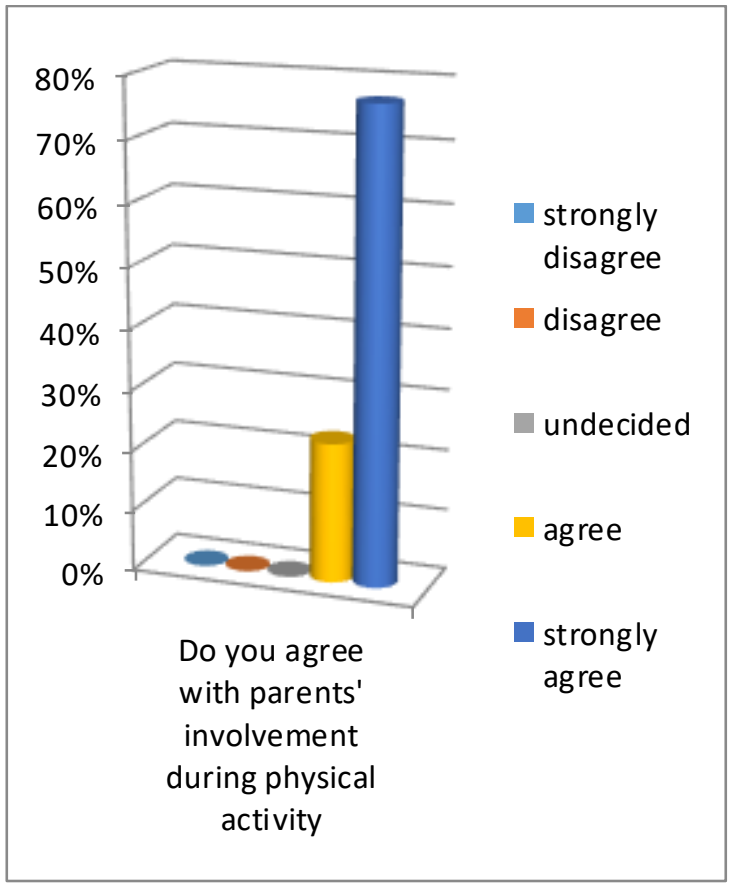

Figure 1. 


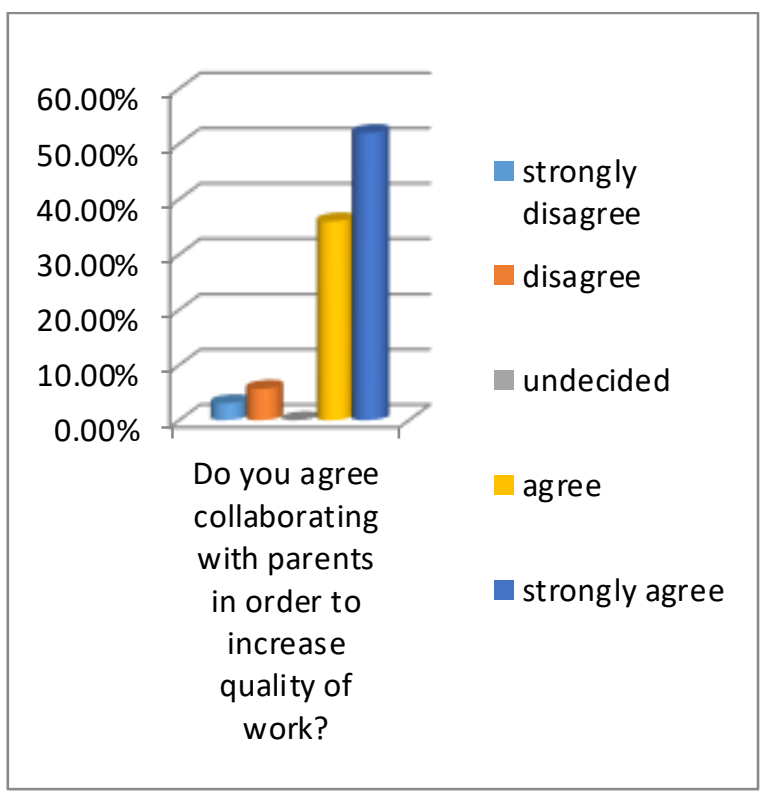

Figure 2.

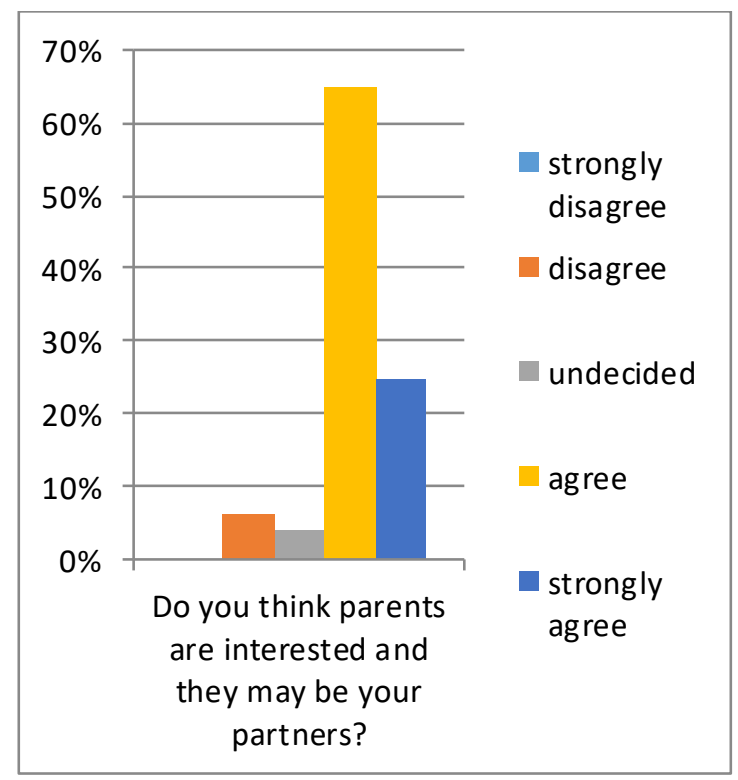

Figure 3 


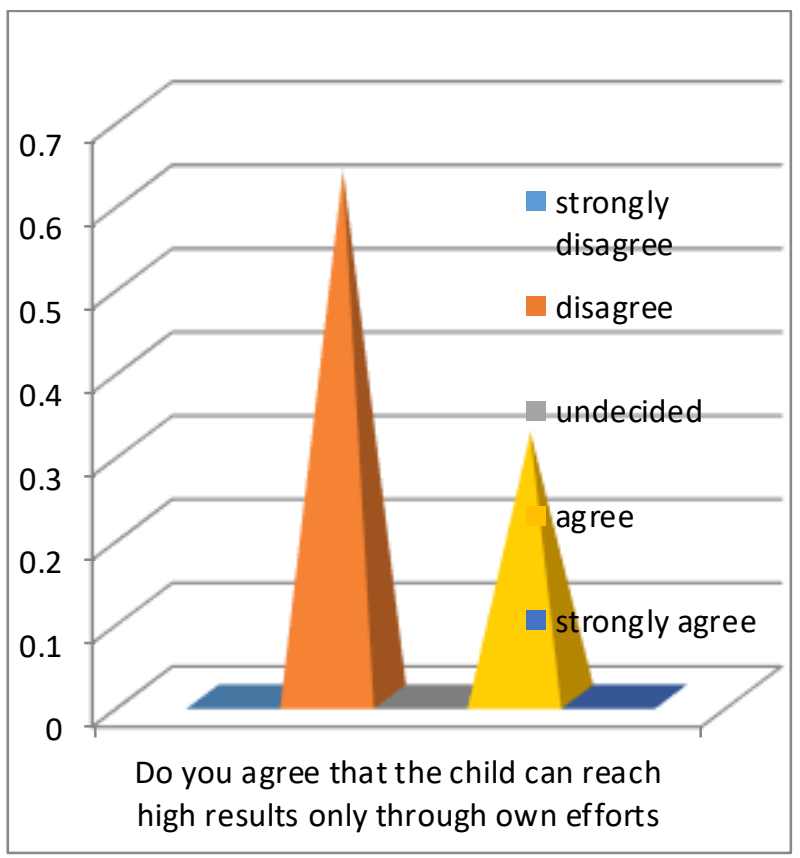

Figure 4

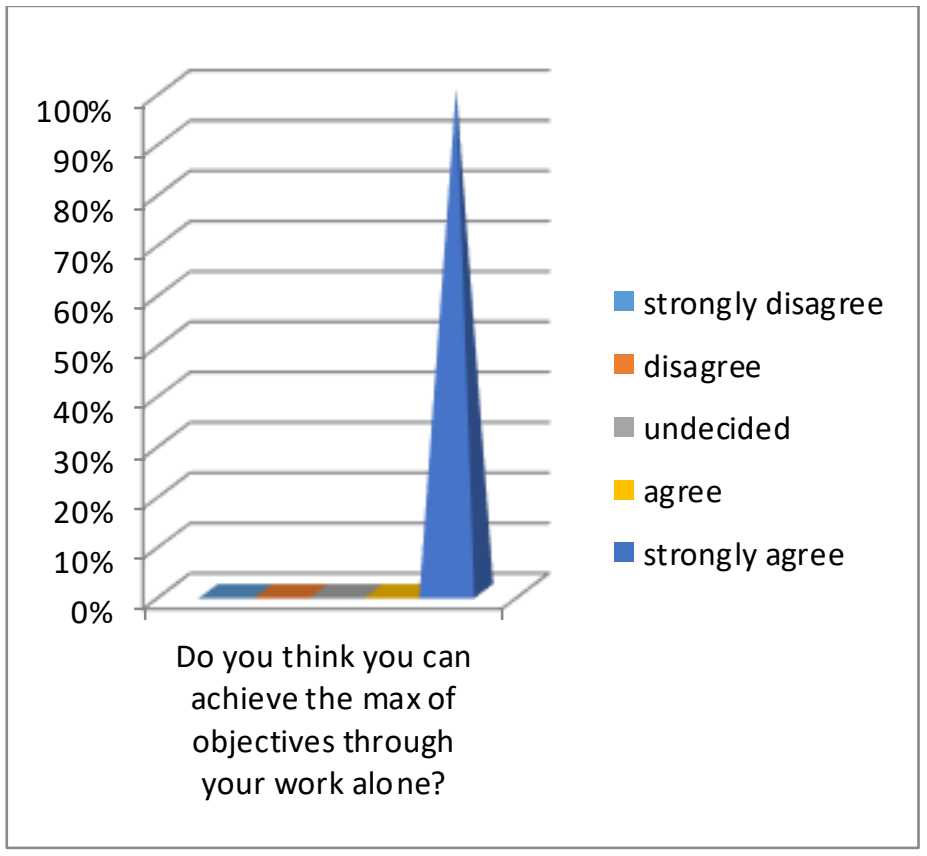

Figure 5 
It is quite obvious that $77 \%$ of teachers and trainers consider important the involvement of parents during physical activity and the results show that the parent-child-specialist partnership triangle is as important as it is in other subjects (Figure 1). On the other hand, even though only $52 \%$ of them strongly agree to collaborate with parents, $36 \%$ agree; there are $8.8 \%$ of them who disagree (Figure 2). While the respondents emphasize that parents are interested in the performance of their children and obtaining high results (Figure 3).

The question - Do you think that you can achieve the max of objectives through your work alone- gets $100 \%$ the answer agree (Figure 5) and this contradicts the result of the question - Do you think that the child can reach high results only through own efforts? - over which $5.4 \%$ strongly disagree, $63 \%$ disagree and $31.6 \%$ agree.

The teachers and trainers are aware of the importance of involvement of parents because the presence of parents of small age groups is important and encouraging results, but we see that the teachers find it difficult to collaborate with parents and involve them with suggestions and consultation based on the result of answers to the survey $-100 \%$ admit that the maximum results may be achieved through their work and $68.4 \%$ admit that the child may reach maximum results only through own efforts.

Results of the questionnaire addressed to parents are as follows:

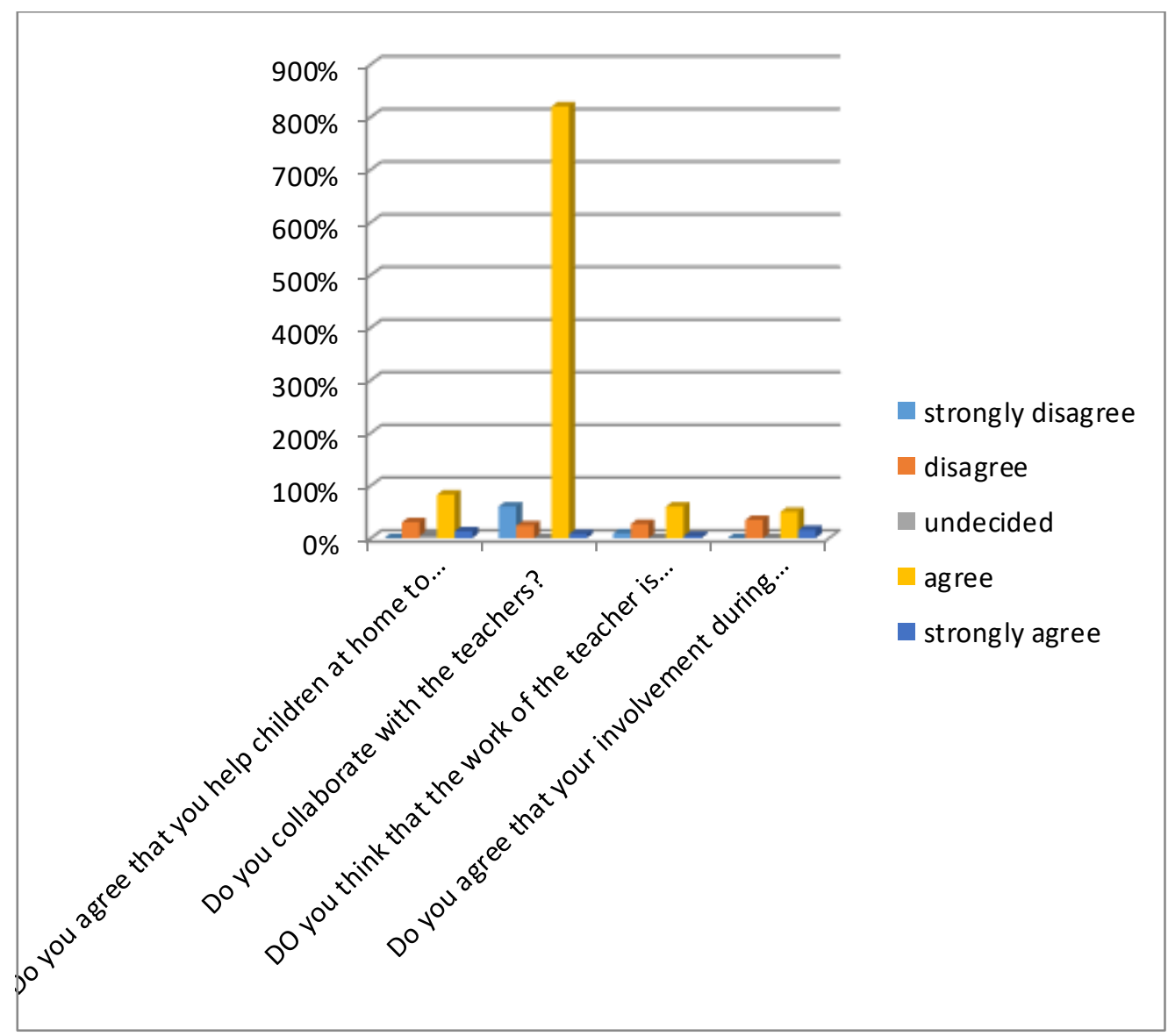

Figure 6 


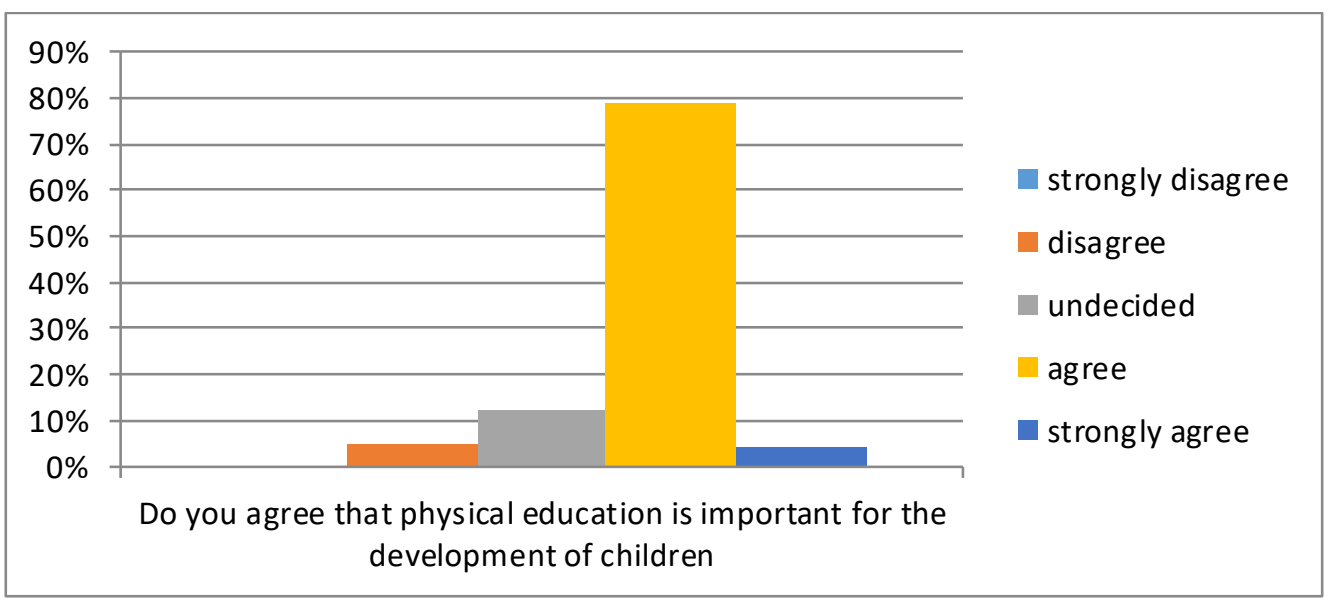

Figure 7

The result shows that parent help children at home and this has an influence in improving their emotional status as a very important element for the development of sports activities. On the other hand, they see collaboration with the parents as very important aspect. There is overall agreement that with the efforts of the trainer/teacher alone, children may not obtain highest results. Most of the respondents consider and accept that physical activity is very important for the psycho-motor development.

\section{Discussion}

Building and developing school-family partnership is one of the current topics of discussion and professional approach of heads of educational, sports establishments, teachers, sports specialists and scientific researcher of this field. This is not only because of the interest of these institutions in improving quality of their service, but also on the fact that the family has a considerable potential and role in the effectiveness of education of children.

The study is focused specifically on this field and the service of responsible structures (school, trainers, teachers etc) and it aims at making not only an analysis of quality of development of this relationship, but also providing an approach concerning this aspect by making it part of the methodology that may be applied in schools and during physical activity outside the institution in order to increase performance of children in the primary cycle of education.

The study analyses several aspects and characteristics which are observed in the experience of our schools and trainers of various sports teams in their cooperation with parents. In this context, the characteristics, barriers and difficulties encountered by the parents in relation to the teachers of physical education who fail to ensure their effective involvement in the education process of their children has been analyzed and presented. The study considering the experience gained and especially the common interest of institutions and parents in the sustainable development of quality in the classes of physical education, introduces and develops the thesis that involvement of and partnership with parents must gain a new dimension, that of commitment of parents in the process of education, specifically learning process. It cannot go without saying that children see their parents as heroes and the latter will be of great help in increasing quality of physical education so as to control and adjust their emotional situation which is an important aspect for their physical activity. Such emotional situation affects to a considerable extent all their actions and behavior. The poor physical condition and frequent tiredness lead to lack of mood of the child and consequently they get angry and bored. As a result they might even abandon classes at school, lack willingness to move and attend various sports with the justification that they are tired, they have headache, their feet hurts etc. This condition will make them even more passive and this will lead to negative consequences on their body. In such cases, intervention of parents with injection of optimism will improve self-confidence which on its turn will be transformed into strength and work by the children. Learning and various sports movement is not tiring if the child has the 
will, interest and motivation. However, interests and will to exercise and learn may be encouraged and stimulated through the parent's example.

Personality is mainly defined by features which do not concern the level of knowledge; instead they are closely linked to fundamental positions and goals of a person. Education does not concern with the mind only; it concerns with the heart and spirit. Life skills are qualities that are developed from various daily life phenomena.

\section{Conclusion}

Teachers and trainers consider important the involvement of parents in this process as they consider it useful in obtaining the intended results based on the specifics of each child. Parents' involvement must be considered an important method to achieve results in efforts of children and teacher's work with the children because involvement of parents has a positive impact on the moral situation of children, building self-confidence and overcoming communication skills with peers and teachers, easily overcoming any embarrassing situation caused because of limited physical capacities etc. To conclude, the role of parents of young age groups is very important because the parent is the best example to be followed by them.

\section{Reference}

[1] Adams, K.S. \& Christenson S.L. (2000). Trust and the family-school relationship: Examination of parentteacher differences in elementary and secondary grades. Journal of School Psychology, 38 (5), 477-497. Aldous, J. (2006). Family, ethnicity, and immigrant youths' educational achievements. Journal of Family Issues, 27(12), 1633-1667.

[2] Allen, J. (2007). Creating welcoming schools: A practical guide to home-school partnerships with diverse families. New York: Teachers College Press.

[3] Altshu, A. (2011) Parental Involvement and the Academic Achievement of Mexican American Youths: What Kinds of Involvement in Youths' Education Matter Most? Social Work Research, Vol 35, Nr3, 159170

[4] Amato, P.R. (2000). The consequences of divorce for adults and children. Journal of Marriage and Family, 62, 1269-1287.

[5] Angel, R., (1936). The family encounters the depression. New York, Charles Scribner's Sons

[6] Annunziata. D, Hogue. A, Faw, L., \& Liddle, H. A (2006) Family Functioning and School Success in AtRisk, Inner-City Adolescents Journal of Youth and Adolescence, Vol. 35, No. 1, pp. 105-113

[7] Antoniou. A.S., Dalla, M., Kashahu, L., Karaj, Dh., Michailidis, G., \& Georgiadi, E. (2013). Socioeconomic Adversity and Family Stressors in Relation to School Achievement Among Greek, Serbian and Albanian Students. In A-S G. Antoniou \& C. L. Cooper (Ed.), The Psychology of recession in the Workplace (pp. 2342). New Horizons in Management.

[8] Astone, N. M., \& McLanahan, S. S. (1991). Family structure, parental practices and high school completion. American Sociological Review, 56(3), 309-320.

[9] AVA, (2011), Raport Vlerësimi i PISA 2009, për matematikën, Raport i pa publikuar

[10] Bailey, L. B., Silvern, S. B., Brabham, E., \& Ross M. (2004). The effects of interactive reading homework and parent involvement on children's inference responses. Early Childhood Education Journal, 32(3), 173178.

[11] Baker, A.J.L., Kessler, S., Piotrkowski, C.S., \& Parker, F.L. (1999). Kindergarten and first-grade teachers' reported knowledge of parents' involvement in their children's education. 
[12] Becker, H. J., and J. L. Epstein. (1982). Parent Involvement: A study of teacher practices. Elementary School Journal

[13] Epstein, J. L. (2001). School, Family, and Community Partnerships:Preparing Educators and Improving Schools. Westview Press, A Member of the Perseus Books Group

[14] Epstein, J. L., and S. L. Dauber. (1989). Teacher attitudes and practices of parent involvement in innercity elementary and middle schools. CREMS Report No 32. Baltimore: John Hopkins University, Center for Research in Elementary and Middle Schools.

[15] Grossman, S. (1999). Examining the Origins of our Beliefs about Parents. Childhood Education. v. 76 no 1. 3.

[16] Hoxhallari, R. Teachers' Beliefs and Practices of Parent Involvement (MSU/USA one school based research study, 2003)

[17] Parent Involvement in the School Life - Albania Study Report, funded by the Education Support Program of Open Society Foundations 9. Advancing Education Quality and Inclusion in the South East Europe Project document

[18] Sheldon, S. B. (2003). Linking school-family-community partnerships in urban elementary schools to student achievement on state tests. Urban Review, 35(2), 149-165

[19] Tichenor, M. S. (1998). Preservice Teachers' Attitudes Toward Parent Involvement:Implications for Teacher Education. The Teacher Educator v. 33 no 4. 